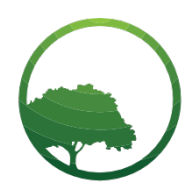

Research in Business \& Social Science

IJRBS VOL 8 NO 5 ISSN: 2147-4478

\title{
Effect of work ethics on job performance with adversity quotient as a mediator
}

\author{
Delon Y.N.Runtu ${ }^{a *}$, Neil Aldrin ${ }^{b}$, Netty Merdiaty $^{c}$ \\ ${ }_{a, b, c}$ Faculty of Psychology, Bhayangkara Jakarta Raya University, Indonesia
}

Crossref

\begin{tabular}{l} 
A R T I C L E IN F O \\
\hline Article history: \\
Received 01 August 19 \\
Received in revs. form 12 August 19 \\
Accepted 04 August 19 \\
\hline Keywords: \\
Work ethics \\
Job Performance \\
Adversity quotient \\
Organizational \\
JEL Classification: \\
O15 \\
L20
\end{tabular}

\begin{abstract}
A B S T R A C T
This study examines the importance of work ethics for employees in the organization towards performance achievement by bringing up the role of adversity quotient mediator. The study aimed to investigate and explore the direct and indirect influence through mediators by using path analysis techniques with the help of AMOS version 24. The process of data collection was carried out using three research variable scales. The number of research respondents is 220 employees. The results of the analysis prove four hypotheses that have been shown to have direct influence, and the role of the mediator is perfect in mediating the two variables. The results of this study can be useful for organizations and practitioners of psychology in industry and organizations.
\end{abstract}

\section{Introduction}

Globalization makes companies compete with each other, many companies have realized it and continue making changes to improve the quality of their employees. This is the impact of extraordinary changes in developing countries almost all over the world. This change certainly occurs in all organizations in developing countries. To achieve this goal companies need the best performance from the resources they have. This human resource is a basic part that needs to be considered by the company, especially at this time, namely when the competition climate is faced by every company. As stated by Aldrin \& Utama (2019), any organization has the same goal in increasing employee productivity because this is important for any organization. Increased employee productivity will affect the overall performance of the organization. This has become one of the important issues in Indonesia. In line with Jalagat (2016), which says that the success of an organization is to have the best assets for the organization, the assets in question are resources owned by the organization. Where employees have work commitments with agencies and employee responsibilities towards the organization. This is in line with Omisore \& Adeleke (2015), that organizational performance is related to human resources in the organization, because it is the most important in every organization. The performance of the entire organization is influenced by the work ethics that exist in its employees. Every organization has set certain goals to be achieved. To achieve this goal, organizations are very dependent on human resource capabilities, which can move the wheels of the organization in a predetermined direction (Aldrin \& Yunanto, 2019).

Having a good work ethic causes a person to make physical, mental, and emotional efforts in his work to fulfill and even exceed expectations. Work ethics can be called a cultural norm that encourages people to take full responsibility for the work they do based on the belief that work has intrinsic value for individuals (Nizam, Nur, Sarah, \& Syafina, 2016). Work ethics refers to the ability to

\footnotetext{
* Corresponding author. ORCID ID: 0000-0001-8990-4695

Peer review under responsibility of Bussecon International Academy.

(C) 2019 Bussecon International. Hosting by SSBFNET- Center for Strategic Studies in Business \& Finance. All rights reserved.

https://doi.org/10.20525/ijrbs.v8i5.457
} 
work in a way that shows ethical commitment to your work and boss. Work ethics is a foundation on which a person's attitude is built. Ethics is related to how a person must behave, while values are mental judgments that determine how a person actually behaves.

Pressure in actual work can lead to creativity, dynamics, and added value for someone. This is if they are not easy to give up or despair, even though the challenges and pressures confront each step of the job. However, workers who tend to have characteristics easily satisfied with what they have achieved and tend to seek security tend to reject any policy changes from the company. Thus employees need an intelligence at work. Of course this intelligence is related to endurance in the face of the work they face everyday. Stoltz (2000), in the 90s in his book entitled Adversity Quotient: Turning Obstacle into Opportunities, introduced a new term Adversity Quotient (AQ).

\section{Literature Review}

\section{Work ethics}

Employees with a work ethic that is stronger than their coworkers are usually more productive. Furthermore Sunanda (2018), emphasizes where ethics refers to the principles that define behavior as true, good and proper. Such principles do not always determine a single "moral" action, but provide a means of evaluating and deciding among competing options. Values involve ethics when they relate to beliefs about what is right and wrong. Ethics is one of the most critical problems in organizations and especially in the management of human resources. A good ethical culture in an organization will provide direction and guidance in various areas to build employees who are united, harmonious and ethical (Nizam et al., 2016). Pojman (1990), shows four areas where ethics are usually conceptualized: Actions, actions (right, wrong, permissive), Consequences (good, bad, indifferent), Character (virtuous, malignant) and Motives (good intentions, intentions evil). According to Sapada, Modding, Gani, \& Nujum (2017), work ethic is employees who have a high commitment to the organization and then are more likely to make changes where the changes do not have the potential to change the basic values and goals of the organization and are considered beneficial to the organization, compared with work ethic employees who are less supportive and less committed to their organizations who are more likely to make changes. Ethics are shaped by habits, cultural influences and the value system that is believed. This ethics evaluates the work both morally and normatively that is felt. Working is good and virtuous in the moral sense is an element of life that is desirable and central in the normative sense, but not necessarily in a moral sense (eg, assuming good). In addition, work is a cognitive category in the knowledge system which consists of the category "how it should be" (Grabowski, 2012). If it is concluded from what was stated above, work ethics is formed from several components such as attitudes, ethics and values that shape the individual character. Where a person's character can be manifested in words and actions (behavior). From what has been described above, it can be used as a hypothesis.

Hypothesis 1: Is there a direct effect of work ethics on job performance?

\section{Adversity quotient}

The success of any organization depends on how its members carry out their duties. If members are effective, efficient and committed to their work, the organization will be able to achieve its mission. However, it cannot be denied that there are many problems every day to be able to do a good job. The existence of a person's personal problems, including the stress that accompanies his work, or the frustration of someone meeting his coworkers every day and the number of unexpected events is a test of resilience to overcome and continue life (Ablaña, Isidro, \& Gino A. Cabrera, 2016). Adversity quotient (AQ) is someone's intelligence in facing obstacles or difficulties regularly. Adversity quotient helps individuals strengthen their abilities and perseverance in facing the challenges of everyday life (Ablaña et al., 2016). Stoltz \& Weihenmayer (2010), asserted that if they could not overcome it and survive then this would make suffering and misery be categorized into four parts, namely physical, emotional, mental, and spiritual. Stoltz (2000) further mentions four dimensions of adversity quotient Control, Origin Ownership, Reach, Endurance abbreviated as $\mathrm{CO}_{2} \mathrm{RE}$. Where each is explained as follows: Control, the ability of individuals to positively influence a situation, and be able to control the response to the situation. Origin Ownership, where the individual's ability to place feelings on him and dare to bear the consequences of the situation, so that it can make improvements to the problems that occur. Reach, an individual's ability to reach out and limit problems so as not to reach other areas of an individual's life. Endurance, the ability of individuals to perceive difficulties, and strength in dealing with these difficulties by creating ideas in problem solving so that the hardness of heart and courage in solving problems can be realized. From what has been described above, it can be used as a hypothesis.

Hypothesis 2: Is there a direct effect of work ethics on adversity quotient?

Hypothesis 3: Is there a direct influence of adversity quotient on job performance?

\section{Job performance}

Job performance. Job performance is related to how individuals perform in their work assignments. In addition to training and natural abilities (such as dexterity or inherent skills), work performance is influenced by workplace environment factors including physically demanding tasks, employee morale, stress levels, and extended working hours. Job performance reflects many important aspects that depend on the growth and production of the company. According to Soysub \& Jarinto (2018), work performance is a behavior that is involved by employees while working which contributes to organizational goals. This behavior is formally evaluated by the organization as part of employee responsibility. To understand and ultimately predict job performance, it is important to be right 
when defining the term. Job performance is about behavior that is in the control of employees and not about results (effectiveness), costs involved in achieving results (productivity), results that can be achieved in a period of time (efficiency), or values and organizations place at the level of performance, effectiveness, certain productivity, or efficiency (utilities). Bevan (2012), emphasizes that work performance is a factor that affects the enormous profitability of each organization.

In line with Muchhal (2014), performance is important for organizations because employee performance leads to business success. Also, performance is important for individuals, because achieving tasks can be a source of satisfaction. However, several factors can affect employee performance such as equipment, physical work environment, meaningful work, standard operating procedures, rewards for good or bad systems, performance expectations, feedback on performance, in addition to the knowledge, skills and attitudes that are indispensable in self employee (Stup, 2003). Borman and Motowidlo (1993), suggest that performance achievements can be divided into two parts, tasks and contextual performance. Task Performance. Task performance involves the effectiveness in which employees carry out activities that formally become part of their work and contribute to the organization's technical core and learn that appropriate performance refers to behaviors that maintain the broad social environment in which the technical core must function. That includes unrestricted behavior that helps organizations function.

Contextual performance. Contextual performance consists of organizational activities that are intentional, not determined by work, and do not contribute directly to the technical core. Contextual performance includes activities such as helping, cooperating with others, and volunteering, which are formally not part of the job but can be important for all jobs. According to Robbins (2011), there are several indicators in measuring employee performance, namely: a). Quality, where this is measured by employee perceptions of the quality of work produced and the task's perfection of the skills and abilities of employees. b). Quantity, the amount generated and expressed in the number of cycles of activity completed. c). Timeliness, level of activity completed at the beginning of the stated time, with output results and maximizing the time available for other activities. d). Effectiveness, the level of use of organizational resources is maximized in order to increase the yield of each unit in the use of resources. e). Independence, the level of an employee who will later be able to carry out his work function on work commitments.

Hypothesis 4: Is there a role for mediator adversity quotient on work ethics and job performance?

\section{Research and Methodology}

This study will test 4 hypotheses using a quantitative approach in which data collection tools use a psychological scale, research respondents are employees in accounting companies in Jakarta-Indonesia. The data analysis technique in this study uses path analysis. To get the value of direct and indirect influence used regression analysis with intervening variables. Respondents in this study were 220 employees.

\section{Measuring instruments}

To collect research data, the authors adopted from original sources that were adapted to local culture and developed research instruments using a psychological scale with a Likert type. There are three scales developed and tested. The scale of ethic work from Pojman (1990), four areas of ethics: Actions, Consequences, Character, and Motives. The scale of Adversity Quotient from Stoltz (2000), mentions Control, Origin Ownership, Reach, Endurance $\left(\mathrm{CO}_{2} \mathrm{RE}\right)$. The work performance scale proposed by Borman and Motowidlo (1993), contextual tasks and performance. The work ethic scale has a reliability coefficient of 0.875 , the Adversity Quotient has a reliability coefficient of 0.867 , the work performance scale has a reliability coefficient of 0.872 . All instruments showed satisfactory reliability, with an Alpha of Cronbach.

\section{Result and Discussion}

Table 1: Descriptive statistics

\begin{tabular}{llcl}
\hline Variable & Mean & Std. Deviation & N \\
\hline Work Ethics & 53,27 & 12,974 & 220 \\
Adversity Quotient & 48,48 & 12,105 & 220 \\
Job Performance & 45,47 & 11,464 & 220 \\
\hline
\end{tabular}

Source: Authors 


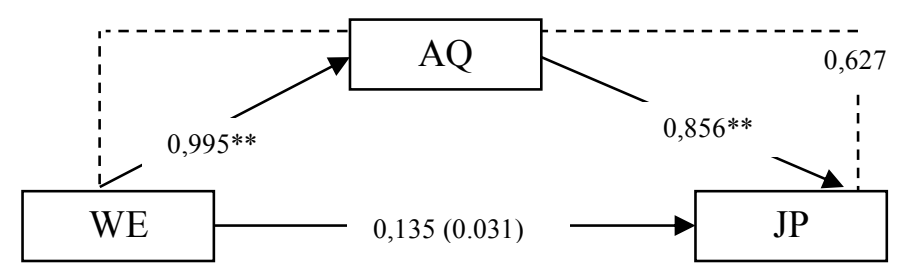

Note: WE, work ethic; AQ, adversity quotient; JP, job performance

Figure 1: WE, AQ, And JP Model

Table 2: Regression Weights, Direct \& Indirect Effects

\begin{tabular}{|c|c|c|c|c|c|c|c|c|}
\hline & & & \multicolumn{2}{|c|}{ Estimate } & \multirow[t]{2}{*}{ S.E. } & \multirow[t]{2}{*}{ C.R. } & \multirow[t]{2}{*}{$\mathrm{P}$} & \multirow[b]{2}{*}{ Indirect Effects } \\
\hline & & & RW & SRW/DI & & & & \\
\hline AQ & 4 & WE & 0.928 & 0.995 & 0.007 & 141.666 & $* * *$ & \\
\hline JP & $\longleftarrow$ & $\mathrm{AQ}$ & 0.815 & 0.861 & 0.059 & 12.043 & $* * *$ & \\
\hline JP & 4 & WE & 0.120 & 0.135 & 0.055 & 2.158 & 0.031 & \\
\hline JP & $\longleftarrow$ AQ & WE & & & & & & 0.0856 \\
\hline
\end{tabular}

Note: WE, work ethic; AQ, adversity quotient; JP, job performance; RW, regression weights; SRW, standardized regression weigths; $\mathrm{SE}$, standard error; $\mathrm{CR}$, critical ratio; $\mathrm{P}$, significant.

Source: Authors

Results in Figure 1. There is a direct relationship of work ethics to adversity quotient, adversity quotient to job performance, work ethics to job performance, and indirect relations work ethics to job performance through adversity quotient. Work ethics has a positive effect on adversity quotient with a standardized coefficient of 0.995 , adversity quotient has a positive effect on job performance with a standardized coefficient of 0.856 , and work ethics has a positive effect on job performance with a standardized coefficient of 0.135 , with a significance value of $0.031<0.000$. The results of path analysis (see figure 1.) show that work ethics has a direct effect on job performance and indirect effect, namely from work ethics to job performance through intervening or mediator variables The magnitude of the indirect effect coefficient is 0.856 . Because the indirect correlation coefficient is greater than the direct relationship coefficient, it can be said that the actual relationship is indirect which can be seen in Figure. 1. So that the mediator can play a very good role.

Table 3: Correlations

\begin{tabular}{llll}
\hline & WE & AQ & JP \\
\cline { 2 - 4 } Work Ethics & 1.000 & & \\
Adversity Quotient & $0.995^{* *}$ & 1.000 & \\
Job Performance & $0.991^{* *}$ & $0.995^{* *}$ & 1.000 \\
\hline
\end{tabular}

Note: Correlation is significant at the 0.01 . WE, work ethic; AQ, adversity quotient; JP, job performance

Source: Authors

The results in table 3 show that the significance value of work ethic with job performance is $0.000<0.05$, which shows a significant correlation between work ethic and job performance. Furthermore, the relationship between adversity quotient and job performance has a significance of $0.000<0.05$, which also proves a significant correlation to the two variables.

Table 4: Assessment of normality

\begin{tabular}{|c|c|c|c|c|c|}
\hline & $\min$ & $\max$ & skew & c.r. & kurtosis c.r. \\
\hline WE & 27.000 & 84.000 & 0.236 & 1.431 & $-0.417-1.264$ \\
\hline $\mathrm{AQ}$ & 25.000 & 77.000 & 0.203 & 1.228 & $-0.462-1.400$ \\
\hline JP & 23.000 & 72.000 & 0.151 & 0.912 & $-0.520 \quad-1.574$ \\
\hline Mulitavriate & & & & & $1.180 \quad 1.597$ \\
\hline
\end{tabular}

Note: WE, work ethic; AQ, adversity quotient; JP, job performance; CR, critical ratio

Source: Authors 
Table 4 above shows the results of the multivariate test of the normality data from this research data as one of the requirements for assumptions to be fulfilled with maximum likelihood. The results in table 4 univariate the value of critical skewness is very low for all the variables below or $<2.58(\mathrm{p}=1 \%)$, so it can be concluded that the research data is normally distributed. Multivariate value of 1.180 with a coefficient of multivariate kurtosis value with a critical value of $1.597<2.58$. So that multivariate data of this study are normally distributed.

\section{Discussion}

The results of the study prove that the four hypotheses proposed proved four accepted hypotheses. From the results of the study, it was found that the mediating effect played a very good role. To improve job performance, employees need a good understanding or understanding of each employee. Understanding and applying it to employees will make them better understand how to be nice to themselves when facing problems, both personally and in carrying out tasks assigned. Ethic work is very necessary for every employee, in order to be able to distinguish between good and not, appropriate or not in being good to fellow colleagues and especially to their leaders. From the results of research (see figure 1.) where work ethics has a direct effect, but with relatively little value, it means that if employees do not know the work ethics in the work in their organization, it is probable that job performance is not optimal even if it is achieved, or it can also means that they cannot separate their personal problems so that they are brought into their work. So that the employee can no longer distinguish between personal and professional. AQ is very functional for employees. When they get a good understanding of AQ, employees know how to behave when there are problems that are being faced both personal and professional. This can be seen from the effect of the work ethics on AQ (see figure.1). As in Fitri's research (2019), which proves that there is an influence of work ethics on adversity quotient. Likewise adveristy quotient $\left(\mathrm{CO}_{2} \mathrm{RE}\right)$ provides a role and influence on employee job performance. Adversity quotient can provide an important role for employees to improve their job performance. Thi (2007), in his research proved the important role of adversity quotient on performance. The same is the case with Irawan \& Yulihasri's research (2019), which said that there was a positive and significant relationship between adversity quotient on employee performance.

\section{Conclusions}

The role of adversity quotient can provide a good and positive contribution for any organization that wants to continue to develop and pay particular attention to the development of each of its employees. Also for practitioners in the field of industrial psychology and organizations. Certainly every organization wants to have resources that maximize performance by being able to balance itself in facing every problem that exists, both in person and professionally. Of course this is also inseparable from the fact that they can be aware of the rules and ethics that exist within the organization. So that they can objectively and positively view every problem that comes to him without harming colleagues and especially the organization. This study examined the importance of work ethics for employees in the organization towards performance achievement by bringing up the role of adversity quotient mediator. In this study, it was also aimed to investigate and explore the direct and indirect influence through mediators by using path analysis techniques with the help of AMOS version 24. The results of the analysis prove four hypotheses that have been shown to have direct influence, and the role of the mediator is perfect in mediating the two variables. The results of this study can be useful for organizations and practitioners of psychology in industry and organizations. However, surely this research has weaknesses, that is, with respondents who are not too large, they cannot generalize the results of this study. It is expected that further research can add other variables, larger and more diverse respondents.

\section{Acknowledgement}

This research received no external funding. The author declares no conflict of interest.

\section{References}

Ablaña, M. V. V, Isidro, D. J., \& Gino A. Cabrera, Mp. (Cand. . (2016). Correlation between Adversity Quotient and Job Performance of LGU Employees of Tayabas City: Input to Effective Public Personnel Management. Journal of Research of the College of Arts and Sciences, Southern Luzon State University, Lucban, Quezon, PH, 8(2), 109-122.

Aldrin, N., \& Utama, A. P. (2019). Analysis of the Effect of Coaching on Teamwork Performance. International Journal of Research in Business and Social Science, 8(3), 24-32. https://doi.org/10.20525/ijrbs.v8i3.253

Aldrin, N., \& Yunanto, K. T. (2019). Job Satisfaction as a Mediator for the Influence of Transformational Leadership and Organizational Culture on Organizational Citizenship Behavior Abstract: The Open Psychology Journal, 126-134. https://doi.org/10.2174/1874350101912010126

Fitri, Y. (2019). The Role of Adversity Intelligence in Encouraging the Implementation of Islamic Work Ethics and the Impact on Accountant's Performance and Career Development of Accountants. The First Economics, Law, Education and Humanities International Conference, KnE Social Sciences, 2019, 619-633. https://doi.org/10.18502/kss.v3i14.4342

Irawan, W., \& Yulihasri. (2019). Effect of Adversity Quotient, Motivation and Discipline on the Performance of Employees PT . PLN ( Persero ) West Sumatra Padang Indonesia. International Journal of Innovative Science and Research Technology, 4(4), 564-568. 
Jalagat, R. (2016). Job Performance, Job Satisfaction and Motivation : A Critical Review of Their Job Performance, Job Satisfaction , and Motivation : A Critical Review of their Relationship. International Journal of Management and Economics, 5, 36-42.

Nizam, S., Nur, M., Sarah, S., \& Syafina, S. (2016). The Relationship between Work Ethics and Job Performance. International Conference on Business and Economics.

Omisore, B. O., \& Adeleke, O. A. (2015). Work Ethics, Values, Attitudes and Performance in the Nigerian Public Service: Issues ,Challenges and the Way Forward. Journal of Public Administration and Governance, 5(1), 157-172. https://doi.org/10.5296/ jpag.v5i1.7367 URL:

Pojman, L. P. (1990). Ethics Discovering Right and Wrong. UNITED STATES MILITARY ACADEMY. Wadsworth Publishing Company I T P An International Thomson Publishing Company.

Sapada, A. F. A., Modding, H. B., Gani, A., \& Nujum, S. (2017). The effect of organizational culture and work ethics on job satisfaction and employees performance. The International Journal of Engineering and Science (IJES), 6(12), $28-36$. https://doi.org/10.9790/1813-0612042836

Soysub, A., \& Jarinto, K. (2018). The Effects Of Multiple Intelligent ( Iq, Eq, And Aq ) On Employee Performance : A Case Of Abc Automotive Co ., Ltd . RMUTT Global Business Accounting and Finance Review (GBAFR), 2(1), 1-12.

Sunanda, K. (2018). Impact Of Work Place Ethics On Employee And Organization Productivity. International Journal of Management (IJM), 9(1), 22-28.

Thi, E. Le. (2007). Adversity Quotient In Predicting Job Performance Viewed Through The Perspective Of The Big Five Master Thesis M Ay 2007. Master Thesis. 